\title{
Mechanical Properties of High Density Polyethylene/Cement Kiln Dust Composite Natural Monomer
}

\author{
Wael Elhrari ${ }^{1 *}$, Salah M Algoul ${ }^{2}$, Abdulbaset M Al-Qish ${ }^{3}$ and Abdalah klash ${ }^{1}$ \\ ${ }^{1}$ Polymer Research Center, Libya \\ ${ }^{2}$ The Higher Institute of Engineering Technology, Libya \\ ${ }^{3}$ Higher Institute of Science and Technology, Libya \\ *Corresponding author: Wael Elhrari, Libya
}

Submission:

\begin{abstract}
A viable solution for reducing the negative environment impact of cement kiln dust (CKD) is to combine with polymeric materials to produce composites materials for many applications in different purposes. In this work, an attempt to investigate the addition of CKD as filler with different load to High density polyethylene (HDPE), also the effect of polyethylene glycol (PEG) as compatibilizer on mechanical properties of the polymer composites. HDPE/CKD composites with various CKD content $(0,2,4,6$, and $8 w t \%)$ samples were prepared by melt extrusion followed by injection molding. The effect of adding $2 \mathrm{wt} \%$ of PEG on mechanical properties of the composites were studied. Tensile strength, impact resistance and, surface hardness was investigated. The results showed improve in tensile strength and elongation at break (\%) of polymer composites with 2 wt $\%$ CKD and reduction in the elastic modulus which attributed to that polymer composite become more ductile and tough. The addition of PEG as compatibilizer showed a significant improvement in mechanical properties that were clear in tensile and impact strength of the polymer composites.
\end{abstract}

Keywords: Cement dust; Compatibilizer effect; Polyethylene composite

\section{Introduction}

Cement industry as many industries produce waste (solid, liquid, gas) which caused environmental pollution, in cement production a solid waste accumulated has negative impact on environment, air, water and land [1]. Although, for several years dramatic advances have been achieved in waste solid management and use of cement kiln dust to reduce the pollution, several industrial applications have been used CKD to minimize its impact on environment [2-6]. Combining CKD with polymer matrix is another solution to minimize the pollution of CKD, the addition of CKD as filler in polymer composites provide some improvement in the polymer properties as well as reducing the cost of production $[7,8]$. In cement chemical structure there are four basic phases $\mathrm{CaO} . \mathrm{SiO}_{2}, \mathrm{CaO} . \mathrm{SiO}_{2}, \mathrm{CaO} \cdot \mathrm{Al}_{2} \mathrm{O}_{3}$, and $\mathrm{CaO} . \mathrm{Al}_{2} \mathrm{O}_{3} \cdot \mathrm{Fe}_{2} \mathrm{O}_{3}$ which can coexist $[1,8]$. CKD consists primarily of calcium carbonate and silicon dioxide which is like the cement kiln raw, but the amount of alkalies, chloride and sulfate is usually considerably higher in the cement dust $[5,6]$. Polymer composites are class of materials where the dispersed filler particles play role of adsorption and redistribution the stress evenly in the matrix. Several studies have been carried out which focused on polyolefin calcium carbonate composites [9-17]. The addition of $\mathrm{CaCO}_{3}$ to high density polyethylene could improve the mechanical and thermal properties without effecting the crystallization of the polymer [12]. The increment is depending on the dispersion, shape, surface area of the particles. However, the poor interfacial adhesion between organic polymers and inorganic fillers weakens the mechanical properties of such composites $[9,10]$. Tanniru \& Misra [11] investigated the micromechanism of plastic deformation during impact for $20 \% \mathrm{CaCO}_{3}$ high density polyethylene their observation was the adoption of $\mathrm{CaCO}_{3}$ in polyethylene has two primary effects: the reinforcement and the nucleating effect. The reinforcement effect increases the bulk crystallinity and modulus, while the nucleating effect decreases the spherulite size, also the addition of $\mathrm{CaCO}_{3}$ to polyethylene increase impact strength and modify the primary micromechamism of plastic from crazing and brittle to particle-induced cavitation and fibrillation. Calcium carbonate surface modified leads to better dispersion of particles and compatibility with a polymers matrix. The addition of compatibilizer increase the interaction thus adhesion between filler particles and polymer, PEG as compatibilizer has been used in polymer composites [18-24]. Few studies address the use of cement dust as filler in polymers, $[7,8,25]$ in this work the effect of CKD as composite filler of high density polyethylene mechanical properties is investigated. In addition, the effect of adding $2 \mathrm{wt} \%$ of polyethylene glycol (PEG) as compatibilizer is studied too. 


\section{Experimental}

\section{Material}

Polyethylene high density (HDPE) was used as matrix (SABIC Saudi Arabia, HDPE F00952, melt flow index 0.05g/10min at $190{ }^{\circ} \mathrm{C}$ and $2.16 \mathrm{Kg}$ ISO 1133 , and value of density is $952 \mathrm{~kg} / \mathrm{m}^{3}$ ISO 1183), Polyethylene glycol $(\mathrm{Mw}=6000)$ (Alfa Aesar) used as received, xylene (Alfa Aesar). Cement kiln dust CKD is supplied by AlBorj cement company (Zliten) Libya, with chemical composition as shown in Table 1, it was sieved to remove impurities and then passed through different sieves size to get particle size of $(<75 \mu \mathrm{m})$

Table 1: Chemical composition of cement kiln dust obtained by XRF.

\begin{tabular}{|c|c|}
\hline Oxide & (\%) \\
\hline $\mathrm{CaO}$ & 43.87 \\
\hline $\mathrm{SiO}_{2}$ & 10.17 \\
\hline $\mathrm{Al}_{2} \mathrm{O}_{3}$ & 1.880 \\
\hline $\mathrm{Fe}_{2} \mathrm{O}_{3}$ & 1.030 \\
\hline $\mathrm{MgO}$ & 0.520 \\
\hline $\mathrm{Na}_{2} \mathrm{O}$ & 2.660 \\
\hline $\mathrm{K}_{2} \mathrm{O}$ & 6.270 \\
\hline $\mathrm{SO}_{3}$ & 1.150 \\
\hline $\mathrm{Cl}$ & 5.600 \\
\hline Free lime & 23.40 \\
\hline
\end{tabular}

\section{Composite preparation}

The HDPE of desire amount was melting in small quantity of xylene and then mixed with 2,4,6, and $8 \mathrm{wt} \%$ CKD in a separate bowl, the mixture then air dried. Then final mixing was carried out using twin screw extruder (HAAKE MiniCTW) with screw speed of (70r.p.m.) and the barrel temperatures set on $190{ }^{\circ} \mathrm{C}$.

Another set of polymer composite were made 2,4,6, and $8 \mathrm{wt} \%$ CKD with 2 wt $\%$ PEG as compatibilizer. The extruded materials were cooled in air and then granules to small pieces. Specimens for tensile strength and impact strength were prepared using injection molding (Xplore 12ml). Details of the composites and codes are reported in Table 2.

Table 2: composites composition and codes.

\begin{tabular}{|c|c|c|c|}
\hline $\begin{array}{c}\text { Composite } \\
\text { Code }\end{array}$ & HDPE wt\% & $\begin{array}{c}\text { Cement Dust } \\
\text { wt\% }\end{array}$ & $\begin{array}{c}\text { Compatibilizer } \\
\text { wt\% }\end{array}$ \\
\hline PE & 100 & 0.0 & --- \\
\hline PEC1 & 98 & 2.0 & --- \\
\hline PEC2 & 96 & 4.0 & --- \\
\hline PEC3 & 94 & 6.0 & --- \\
\hline PEC4 & 92 & 8.0 & 2.0 \\
\hline PEC1-PEG & 96 & 2.0 & 2.0 \\
\hline PEC2-PEG & 94 & 4.0 & 2.0 \\
\hline PEC3-PEG & 92 & 6.0 & 2.0 \\
\hline PEC4-PEG & 90 & 8.0 & - \\
\hline
\end{tabular}

\section{Characterization}

Mechanical properties of the prepared polymer cement dust composites were investigated. Tensile properties were investigated by using the Universal Tensile testing machine Prodit 3kN operating at a crosshead speed of $5 \mathrm{~mm} / \mathrm{min}$ at a room temperature. Charpy impact test was carried out using (CEAST Resil Impactor tester) at room temperature with impact energy of 15J, The specimens for impact test were prepared and notched according to ASTM (D25687). A minimum of four specimens were tested and average value were taking. Hardness properties were investigated by a Shore Durometer in Shore D scale at room temperature according to ASTM D 2240.

\section{Results and Discussion}

Figure 1 shows the effect of CKD content on the tensile strength of the polymer composites prepared using melt extrusion, also the effect of adding $2 w t \%$ PEG as compatibilizers. It can be seen the addition of CKD to polymer matrix reduced the value of tensile strength of the composites compared with neat polymer, that expected when adding rigid particles into polymer matrix, [26] mechanical properties of polymer composites can be altered by various factor: properties of the polymer matrix, filer particles size and morphology, particles loading and distribution, interfacial adhesion between filler particles and matrix [26-28]. A poor dispersion of the CKD particles could create stress concentrations spot in the matrix. Ineffective dispersion also leads to particles aggregations which lower the surface area and interfacial interaction and adhesion. However, at $2 \mathrm{wt} \%$ CKD modest increases in tensile strength value were observed, as result of good interaction and dispersion of the particles, thus better adhesion between CKD particles and polymer matrix. In contrast the additions of $2 \mathrm{wt} \% \mathrm{PEG}$ as compatibilizer into the composites, shown visible improvement in tensile strength of the composites at different CKD content, as result of an excellent interaction between CKD particles and polymer matrix. Besides to a good dispersion of CKD particles, lead to increase of surface area of the filler consequently thus, reduce stress concentration spot. A significant improvement was observed in particular at high CKD content (4wt $\%$ and, $6 \mathrm{wt} \%)$.

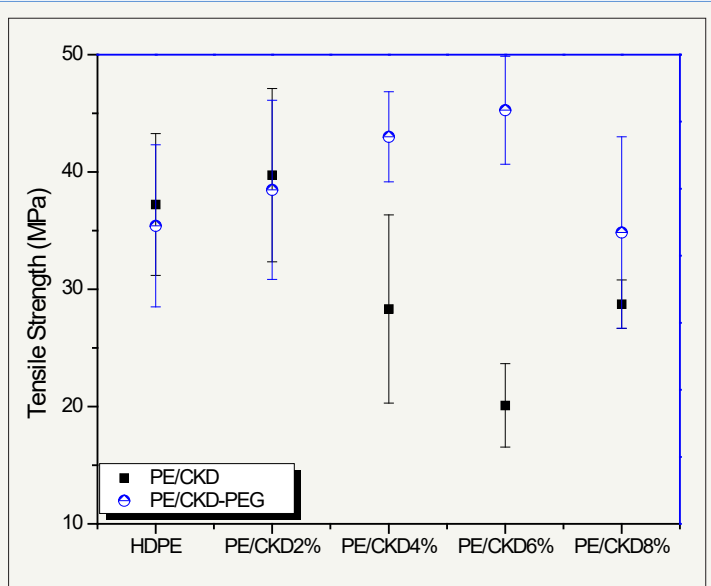

Figure 1: Tensile strength of $\mathrm{PE} / \mathrm{CKD}$ composites and PE/ CKD-PEG. 
Figure 2 shows the effect of CKD content on the elastic modulus of the polymer composites prepared using melt extrusion, also the effect of adding $2 \mathrm{wt} \%$ PEG as compatibilizers. A slight decrease in the value of the elastic modulus for all polymer composites with various CKD content is observed. Once more poor dispersion of CKD particles leads to low surface area thus weak adhesion. Once more the addition of $2 \mathrm{wt} \%$ PEG as compatibilizer gain a significant improve in elastic modulus obtained in PE/CKD2\%-PEG2\% follow by, a significant decrease in the value of the elastic modulus for other polymer composites with different CKD content.

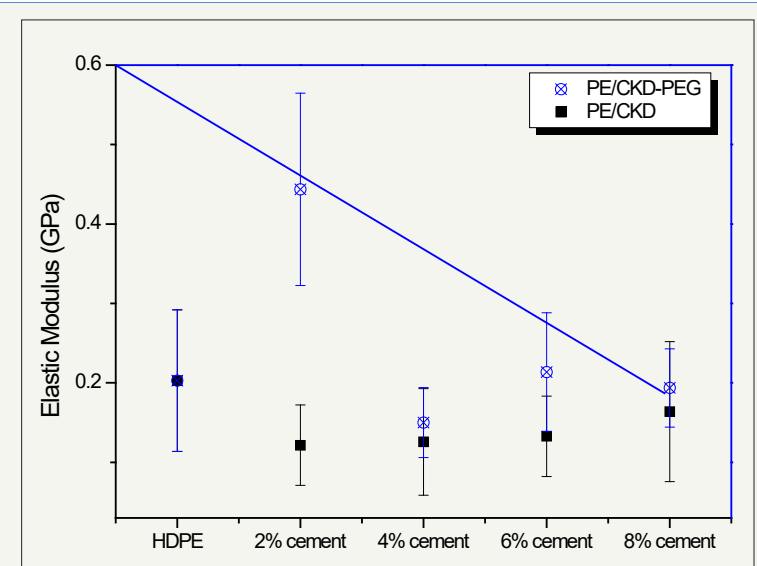

Figure 2: Elastic modulus of $\mathrm{PE} / \mathrm{CKD}$ composites and $\mathrm{PE} /$ CKD-PEG.

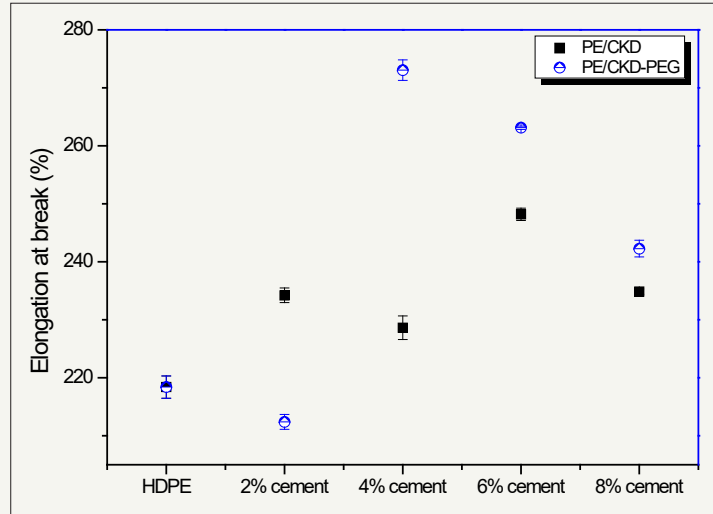

Figure 3: Elongation at break (\%) of $\mathrm{PE} / \mathrm{CKD}$ composites and PE/CKD-PEG.

Figure 3 shows the effect of CKD content on elongation at break of the polymer composites prepared using melt extrusion, also the effect of adding $2 w t \%$ PEG as compatibilizers. An increase in the value of elongation at break of all polymer composites with different CKD content was observed, the mechanism of fracture for poor interfacial adhesion the cracks start from the pole of the filler surface and form a huge number of microvoids between the filler and matrix. The microvoids are dragged along the direction of the stress. This fracture mechanism leads to a low tensile strength and relatively high elongation [29]. Further increase in the value of elongation occurred with addition of PEG. At PE/CKD2\%-PEG2\% the value of elongation at break decreased, that due to good interfacial adhesion where the cracks start from the equator of the filler and develop in the matrix or along the interface. Such fracture mechanism leads to a high tensile strength and low elongation.

Table 3 shows the average values and standard deviation of impact strength and hardness of the composites. Impact strength of PE and PE/CKD, PE/CKD-PEG composites are listed. A virgin PE exhibited impact strength of $12 \mathrm{~kJ} / \mathrm{m}^{2}$. This value increased with addition of $2 \mathrm{wt} \%$ CKD then decreased with the addition of $4 \mathrm{wt} \%$ $\mathrm{CKD}$, then retain the impact strength value with $6 \mathrm{wt} \% \mathrm{CKD}$ and then decrease yet again at $8 w t \%$ CKD. The aggregation of the CKD particles at high CKD content is believing to be the responsible for the decrease in impact strength. Increase in CKD particles lead to possibility for the CKD particles to aggregate and form separate phase in the polymer matrix, therefore decrease the surface area of the particles thus lowering the adhesion between the polymer matrix and CKD particles.

Table 3: Impact strength and hardness of the PE/CKD composites.

\begin{tabular}{|c|c|c|c|c|}
\hline Sample & $\begin{array}{c}\text { Average Impact } \\
\text { strength } \mathbf{( k J / \mathbf { m } ^ { 2 } \text { ) }}\end{array}$ & STD & $\begin{array}{c}\text { Average } \\
\text { Hardness }\end{array}$ & STD \\
\hline PE & 12.1 & 1.5 & 62.0 & 2.0 \\
\hline PE/CKD2\% & 14.6 & 1.3 & 64.8 & 0.7 \\
\hline PE/CKD4\% & 10.6 & 2.0 & 63.8 & 1.7 \\
\hline PE/CKD6\% & 12.2 & 1.6 & 63.1 & 2.4 \\
\hline PE/CKD8\% & 10.3 & 1.3 & 63.5 & 2.1 \\
\hline $\begin{array}{c}\text { PE/CK- } \\
\text { D2\%-PEG2\% }\end{array}$ & 11.9 & 2.0 & 63.1 & 1.0 \\
\hline $\begin{array}{c}\text { PE/CK- } \\
\text { D4\%-PEG2\% }\end{array}$ & 17.0 & 4.0 & 61.3 & 0.5 \\
\hline $\begin{array}{c}\text { PE/CK- } \\
\text { D6\%-PEG2\% }\end{array}$ & 12.7 & 1.9 & 62.2 & 1.0 \\
\hline $\begin{array}{c}\text { PE/CK- } \\
\text { D8\%-PEG2\% }\end{array}$ & 12.7 & 1.9 & 63.5 & 1.3 \\
\hline
\end{tabular}

Although PE/CKD 2\% showing an increase in impact strength comparing to neat PE as result of good dispersion of CKD in PE matrix. Similar results observed with $2 \mathrm{wt} \%$ kaolin clay added to identical PE grade as in previous work [30]. The addition of $2 \mathrm{wt} \%$ PEG to the polymer composites exhibited slight improve in impact strength of the composites, as result of good adhesion between CKD and polymer matrix without considering the dispersion of the CKD particles. Compatibilizers are commonly added to the polymer composites to improve the interfacial adhesion, between the filler particles and polymer matrix. PE/CKD4\%-PEG2\% showing significant increase in impact strength compared with neat PE this result indicate improvement in adhesion between the particles and polymer matrix, consequently, a better dispersion of the particles so that the surface area of CKD particles increased. Shore hardness D property of the polymer composites are listed in Table 3. Slight increase observed in the values of hardness at all polymer composites. The effect of PEG on the surface hardness was by reducing the value of the hardness at all composites content. 


\section{Conclusion}

Solid waste cement kiln dust which has a negative impact on the environment can be used as filler for polymer composites even without any modification. The composites were prepared by melt extrusion mixing of high density polyethylene with varying amounts of cement dust (2,4,6,8 wt\%). Mechanical properties of the polymer composites showed improvement in tensile strength of polymer composites with $2 \mathrm{wt} \% \mathrm{CKD}$, as well as increasing in the elongation at break (\%) at same CKD content. In contrast, the reduction of the elastic modulus means that polymer composites become more ductile and tough. The study revealed that the impact strength and surface hardness increased at 2wt\% CKD content. Moreover, the addition of PEG as compatibilizer showed a significant improvement in mechanical properties that was clear in tensile and impact strength of the polymer composites. The improvement in the mechanical properties can be obtained at low CKD loading of $2 \mathrm{wt} \%$. Higher CKD content produced inferior mechanical properties probably due to agglomeration and less interaction between CKD particles and polymer matrix. The addition of $2 \mathrm{wt} \%$ PEG leads to increase the amount of CKD content in the polymer composites without sacrificing the mechanical properties whereas greater properties can be obtained at less than 6wt\% CKD. PEG addition plays a vital role in increasing the interaction between CKD particles and polymer matrix therefore, good dispersion of CKD particles in the polymer matrix.

\section{References}

1. Raajasubramanian D, Sundaramoorthy P, Baskaran L, Ganesh KS Chidambaram AA, et al. (2011) Cement dust pollution on growth and yield attributes of groundnut. International Multidisciplinary Research Journal 1: 31-36.

2. Ahmed HY, Othman AM, Mahmoud AA (2006) Effect of using waste cement dust as a mineral filler on the mechanical properties of hot mix asphalt. Assiut University Bulletin for Environmental Researches 9(1): 51-59.

3. Ahmed A, Shehata M, Easa S (2009) Use of factory-waste shingles and cement kiln dust to enhance the performance of soil used in road works. Advances in Civil Engineering, pp. 1-9.

4. Aziz E, Altohamy AK, Towfeek AR (2010) Physical and chemical properties for stabilized sand using cement kiln dust. Journal of Engineering Sciences, Assiut University 38(3): 655-669.

5. Maslehuddin M, Al-Amoudi OSB, Shameem M, Rehman MK, Ibrahim M (2008) Usage of cement kiln dust in cement products-research review and preliminary investigations. Construction and Building Materials 22: 2369-2375.

6. Adaska WS, Taubert PEDH (2008) Beneficial uses of cement kiln dust IEEE/PCA $50^{\text {th }}$ Cement industry Technical Conf. FL, USA.

7. Asaad JN, Tawfik SY (2011) Polymeric composites based on polystyrene and cement dust wastes. Materials and Design 32(10): 5113-5119.

8. Krysztafkiewicz A, Jesionowski T, Rager B (1997) Reinforcing of synthetic rubber with waste cement dust modified by coupling agents. Journal of adhesion science and technology 11(4): 507-517.

9. Oliveira AG, Silva AL, Sousa AM, Leite MC, Jandorno JC, et al. (2016) Composites based on green high-density polyethylene, polylactide and nanosized calcium carbonate: Effect of the processing parameter and blend composition. Materials Chemisrty and Physics 181: 344-351.

10. Elleithy RH, Ali I, Ali MA, Al-Zahrani SM (2010) High density polyethylene/micro calcium carbonate composites: A study of the morphological, thermal, and viscoelastic properties. Journal of Applied polymer science $117(4)$ : 2413-2421.

11. Tanniru M, Misra RDK (2005) On enhanced impact strength of calcium carbonate-reinforced high-density polyethylene composites. Materials Science and Engineering A 405(1-2): 178-193.

12. Ahn Y, Ahn JW, Han C (2017) Thermomechanical characteristics of $\mathrm{HDPE} / \mathrm{CaCO}_{3} / \mathrm{LDPE}-\mathrm{g}-\mathrm{MA}$ composites for melt-mixing conditions. Journal of Ceramic Processing Research 18(2): 127-136.

13. Zhang L, Wang ZH, Huang R, Li LB, Zhang XY (2002) PP/elastomer/ calcium carbonate composites: effect of elastomer and calcium carbonate contents on the deformation and impact behavior. Journal of Materials Science 37(13): 2615-2621.

14.Wang WY, Zeng XF, Wang GQ, Chen JF (2007) Preparation and characterization of calcium carbonate/ low-density-polyethylene nanocomposites. Journal of Applied polymer science 106(3): 1932 1938.

15. Rai US, Singh RK (2003) Synthesis and mechanical characterization of polymer-matrix composites containing calcium carbonate/ white cement filler. Materials Letters 58(1-2): 235-240.

16. Ayae S, Takashi K (2004) Calcium carbonate/ polymer composites: polymorph control for aragonite. Composite interfaces 11(4): 287-295.

17. Teixeira SCS, Moreira MM, Lima AP, Santos LS, Rocha BM, et al. (2006) Composites of high density polyethylene and different grades of calcium carbonate: mechanical, rheological, thermal, and morphological properties. Journal of Applied polymer science 101(4): 2559-2564.

18. Chaudhry AU, Mittal V (2013) High-density polethylene nano composites using masterbatches of chlorinated polyethylene/gtaphene oxide. Polymer Engineering and Science 53(1): 78-88.

19. As'habi L, Jafari SH, Khonakar HA, Boldt R, Wagenknecht U, et al. (2013) Tuning the processability, morphology and biodegradability of clay incorporated PLA/LLDPE blends via selective localization of nano clay induced by melt mixing sequence. eXPRESS Polymer Letters 7(1): 21-39.

20. Pegoretti A, Dorigato A, Penati A (2007) Tensile mechanical response of polyethylene-clay nanocomposites. eXPRESS Polymer Letters 1(3): 123-131.

21. Dong Y, Bhattacharyya D (2008) Effects of clay type, clay/compatibiliser content and matrix viscosity on the mechanical properties of polypropylene/organoclay nanocomposites. Composites: Part A 39: 1177-1191.

22. Salmah AG, Hazwan K (2008) Low density polyethylene-nano clay composites: the effect of poly(acrylic acid) on mechanical properties, XRD, morphology properties and water absorption. Malaysian Polymer Journal 3(2): 39-53.

23. Tajeddin B (2015) A comarison of MAPE and PEG effects on the mechanical characteristics of wheat straw/LDPE biocomposites for packaging application. Polymer \& Polymer Composites 23(9): 663-668.

24. Pracella M, Haque MMU, Alvarez V (2010) Functionalization, compatibilization and properties of polyolefin composites with natural fibers. Polymers 2(4): 554-574

25. Hussain AI, El-Sabbagh SH, Abadir IF (2003) Cement dust as filler in NBR vulcanizates. Journal of Elastomers and Plastics 35(2): 161-179.

26. Nielsen LE, Landel RF (1994) Mechanical properties of polymers and composites. Marcel Dekker, New York, USA.

27. Chu D, Nguyen Q, Baird DG (2007) Effect of matrix molecular weight on the dispersion of nano clay in unmodified high density polyethylene. Polymer Composites 28(4): 499-511.

28. Merinska D, Kubisova H, Kalendova A, Svoboda P, Hromadkova J (2011) Processing and properties of polyethylene/montmorillonite nanocomposites. Journal of Thermoplastic Composite Materials 25(1): 115-131. 
29. Tanasa F, Zanoaga M, Darie R (2014) Evaluation of stress-strain properties of some new polymer-clay nanocomposites for aerospace and defense applications. International Conference of Scientific Paper AFASES, Brasov, Romania.
30. Shebani A, Elhrari W, Klash A, Aswei A, Omran K, et al. (2016) Effects of Libyan kaolin clay on the impact strength properties of high density polyethylene/clay nanocomposites. International Journal of Composite Materials 6(5): 152-158.

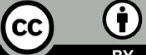

Creative Commons Attribution 4.0 International License

For possible submissions Click Here
Submit Article

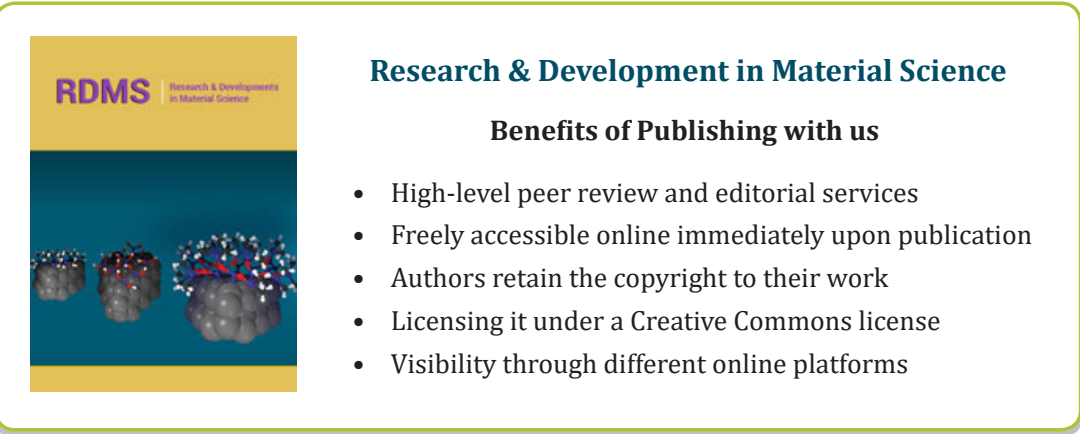

